Review

\title{
A Systematic Review of the Efficacy and Safety of Direct Oral Anticoagulants in Atrial Fibrillation Patients with Diabetes Using a Risk Index
}

\author{
Domenico Acanfora ${ }^{1, *}$, Marco Matteo Ciccone ${ }^{2}$, Valentina Carlomagno ${ }^{1}$, Pietro Scicchitano ${ }^{2,3}$, \\ Chiara Acanfora ${ }^{1,4}$, Alessandro Santo Bortone ${ }^{5}$, Massimo Uguccioni ${ }^{6}$ and Gerardo Casucci ${ }^{1, *}$
}

Citation: Acanfora, D.; Ciccone, M.M.; Carlomagno, V.; Scicchitano, P. Acanfora, C.; Bortone, A.S.;

Uguccioni, M.; Casucci, G. A Systematic Review of the Efficacy and Safety of Direct Oral Anticoagulants in Atrial Fibrillation Patients with Diabetes Using a Risk Index. J. Clin. Med. 2021, 10, 2924. https:// doi.org/10.3390/jcm10132924

Academic Editors: Michał Ciurzyński and Justyna Domienik-Karłowicz

Received: 31 May 2021

Accepted: 26 June 2021

Published: 29 June 2021

Publisher's Note: MDPI stays neutral with regard to jurisdictional claims in published maps and institutional affiliations.

Copyright: (c) 2021 by the authors Licensee MDPI, Basel, Switzerland. This article is an open access article distributed under the terms and conditions of the Creative Commons Attribution (CC BY) license (https:// creativecommons.org/licenses/by/ $4.0 /)$
1 Unit of Internal Medicine, San Francesco Hospital, Viale Europa 21, 82037 Telese Terme, Italy; vale.carlomagno@gmail.com (V.C.); acanforachiara@gmail.com (C.A.)

2 Section of Cardiovascular Diseases, Department of Emergency and Organ Transplantation, School of Medicine, University of Bari, Piazza Umberto I, 1, 70121 Bari, Italy; marcomatteo.ciccone@uniba.it (M.M.C.); piero.sc@hotmail.it (P.S.)

3 Cardiology Unit, Hospital "F. Perinei”, Strada Statale 96 per Gravina in Puglia, 70022 Altamura, Italy

4 Department of Biotechnological and Applied Clinical Sciences, University of L'Aquila, 67100 L'Aquila, Italy

5 Division of Cardiac Surgery, Department of Emergency and Organ Transplantation, University of Bari, 70121 Bari, Italy; alessandro.bortone@gmail.com

6 Cardiology Unit, San Camillo Hospital, 00152 Rome, Italy; muguccioni@hotmail.com

* Correspondence: domenico.acanfora29@gmail.com (D.A.); segr.dott.gerardocasucci@virgilio.it (G.C.); Tel.: +39-0824-9747-26 (G.C.)

Abstract: Diabetes mellitus (DM) represents an independent risk factor for chronic AF and is associated with unfavorable outcomes. We aimed to evaluate the efficacy and safety of direct oral anticoagulants (DOACs) in patients with atrial fibrillation (AF), with and without diabetes mellitus $(\mathrm{DM})$, using a new risk index (RI) defined as: $\mathrm{RI}=\frac{\text { Rate of Events }}{\text { Rate of Patients at Risk }}$. In particular, an RI lower than 1 suggests a favorable treatment effect. We searched MEDLINE, MEDLINE In-Process, EMBASE, PubMed, and the Cochrane Central Register of Controlled Trials. The risk index (RI) was calculated in terms of efficacy (rate of stroke/systemic embolism (stroke SEE)/rate of patients with and without DM; rate of cardiovascular death/rate of patients with and without DM) and safety (rate of major bleeding/rate of patients with and without DM) outcomes. AF patients with DM $(n=22,057)$ and 49,596 without DM were considered from pivotal trials. DM doubles the risk index for stroke/SEE, major bleeding (MB), and cardiovascular (CV) death. The RI for stroke/SEE, MB, and CV death was comparable in patients treated with warfarin or DOACs. The lowest RI was in DM patients treated with Rivaroxaban (stroke/SEE, RI = 0.08; CV death, $\mathrm{RI}=0.13$ ). The RIs for bleeding were higher in DM patients treated with Dabigatran (RI110 $=0.32$; RI150 $=0.40$ ). Our study is the first to use RI to homogenize the efficacy and safety data reported in the DOACs pivotal studies against warfarin in patients with and without DM. Anticoagulation therapy is effective and safe in DM patients. DOACs appear to have a better efficacy and safety profile than warfarin. The use of DOACs is a reasonable alternative to vitamin-K antagonists in AF patients with DM. The RI can be a reasonable tool to help clinicians choose between DOACs or warfarin in the peculiar set of AF patients with DM.

Keywords: atrial fibrillation; DOACs; diabetes mellitus; risk index

\section{Introduction}

Atrial fibrillation (AF) is the most common arrhythmia worldwide. The prevalence of $\mathrm{AF}$ is expected to increase 2.5-fold in the next 50 years due to the growing mean age of the population [1]. Diabetes can be considered a pandemic too [2,3]. Diabetes mellitus (DM) represents an independent risk factor for chronic AF [4]. The development of AF is likely to be multifactorial and the mechanism is elusive, while evidence is emerging on the correlation between AF and DM [4]. DM and AF certainly share common risk 
factors, including hypertension, dyslipidemia, atherosclerosis, and obesity. Populationbased studies suggested that DM is an independent risk factor for atrial fibrillation [5]. In patients with hypertension, DM did not act as an independent predictor for new onset AF in a post-hoc analysis from ALLHAT [6]. Nevertheless, a retrospective analysis of the VALUE study showed that hypertensive patients with new onset DM had a significantly higher event rate of new onset AF compared to patients without DM, even after adjusting for body mass index [7]. On the other hand, DM is one of the most common concomitant diseases in patients with AF [8]. Indeed, DM and AF are both predictors for stroke and mortality [9].

DM itself is associated with increased thrombin production and consequently may increase thromboembolic risk $[10,11]$. Anticoagulation therapy is mandatory in DM patients with AF. The use of VKA in these patients is to be implemented with caution. Hyperglycemia induces an increase in glycated albumin in DM patients. Glycated albumin has a reduced binding affinity for warfarin, resulting in a higher free fraction of the anticoagulant [12]. Consequently, there is a greater variability of the INR in AF patients with an increased risk of Stroke/SEE and MB [13].

Prevention of thromboembolic events was improved with the use of direct oral anticoagulants (DOACs) (Dabigatran, Rivaroxaban, Apixaban, and Edoxaban), which overcame the limitations of therapeutic standard of dose-adjusted vitamin $\mathrm{K}$ antagonists (VKAs) [14-18]. These drugs were approved based on the results from their respective dose-adjusted phase III, warfarin-controlled, randomized controlled trials (RCTs) [14-17].

The proportion of patients with DM enrolled in the four trials was $23 \%$ in the Randomized Evaluation of Long-Term Anticoagulant Therapy (RE-LY) study, 40\% in the Rivaroxaban Once-daily oral direct factor Xa inhibition Compared with vitamin $\mathrm{K}$ antagonism for prevention of stroke and Embolism Trial in Atrial Fibrillation (ROCKET-AF) study, $25 \%$ in the Apixaban for Reduction in Stroke and Other Thromboembolic Events in Atrial Fibrillation (ARISTOTLE) study, and 36\% in the Effective Anticoagulation With Factor Xa Next Generation in Atrial Fibrillation (ENGAGE-AF TIMI 48) study [14-17].

This systematic review aimed at evaluating the efficacy and safety of DOACs versus warfarin in patients with $\mathrm{AF}$, with and without $\mathrm{DM}$, by applying the risk index (RI) proposed by Uguccioni et al. $[19,20]$.

\section{Methods}

We performed an extensive literature search to identify studies reporting stroke and systemic embolism, major bleeding, and cardiovascular $(\mathrm{CV})$ death in patients with $\mathrm{AF}$, randomized to VKA or DOAC, with and without DM. The search was performed in MEDLINE, MEDLINE In-Process, and Other Non-Indexed Citations, EMBASE, PubMed, and the Cochrane Central Register of Controlled Trials through the Ovid interface to identify English-language clinical articles published from 2002 (first marketed DOAC) to February 2020 related to phase III RCTs of dabigatran, rivaroxaban, apixaban, or edoxaban versus warfarin for the prevention of thrombotic events in AF patients. Keywords used were: "atrial fibrillation", "warfarin", "oral thrombin inhibitor", "oral factor Xa inhibitor", "dabigatran", "rivaroxaban", "apixaban", "edoxaban", and "diabetes".

We also established regular alerts and complemented the electronic search strategy with a direct, manual reference review.

Systematic reviews, which included RCTs that evaluated stroke/systemic embolic events (SEE), major bleeding, and/or cardiovascular (CV) death and evaluated DOACs and VKAs were eligible for inclusion. PICOS (patients, intervention, comparator, outcomes, and study design) criteria for inclusion and exclusion of network meta-analyses (NMAs) are described in Table 1. 
Table 1. PICOS criteria for inclusion and exclusion of systematic review.

\begin{tabular}{|c|c|c|}
\hline & Inclusion Criteria & Exclusion Criteria \\
\hline Population & $\begin{array}{l}\text { Patients with NVAF receiving any of the } \\
\text { treatments below. All studies in the SLR } \\
\text { must include } \geq 90 \% \text { patients with NVAF. } \\
\text { SLRs including studies with }<90 \% \text { patients } \\
\text { with NVAF must report data separately for } \\
\text { the NVAF studies }\end{array}$ & $\begin{array}{c}\text { Not a population of interest (ie, } \\
\text { non-NVAF patients) } \\
\text { Studies of patients receiving ablation, } \\
\text { cardioversion, or left-atrial appendage closure }\end{array}$ \\
\hline Intervention/comparator & $\begin{array}{c}\text { DOACs (apixaban, dabigatran, rivaroxaban, } \\
\text { edoxaban) and warfarin studies need to have } \\
\text { compared } 1 \text { or more DOACs and/or warfarin } \\
\text { Clinical outcomes: }\end{array}$ & $\begin{array}{c}\text { Studies not reporting outcomes for population } \\
\text { of interest }\end{array}$ \\
\hline Study design & $\begin{array}{l}\text { - } \text { Stroke/systemic embolism } \\
\text { Major bleeding (ISTH or modi- } \\
\text { fied ISTH). } \\
\text { Cardiovascular death } \\
\text { Patients with and without } \\
\text { diabetes mellitus } \\
\text { Doses included: } \\
\text { Apixaban: } 5 \text { or } 2.5 \mathrm{mg} \text { a } \\
\text { Rivaroxaban: } 20 \text { or } 15 \mathrm{mg} \\
\text { Dabigatran: } 150 \text { or } 110 \mathrm{mg} \\
\text { Edoxaban: } 30 \text { or } 60 \mathrm{mg} \\
\text { SLR of randomized controlled trials }\end{array}$ & $\begin{array}{c}\text { SLRs/NMAs of observational studies, } \\
\text { nonsystematic reviews, primary research trials, } \\
\text { primary observational studies, case reports, case } \\
\text { series, narrative reviews } \\
\text { Letters to the editor, guidelines, } \\
\text { meeting abstracts } \\
\text { In vitro pharmacodynamic or pharmacokinetic } \\
\text { studies only, animal studies, genetic studies only }\end{array}$ \\
\hline
\end{tabular}

PICOS, patients, intervention, comparator, outcomes, study design; DOAC, direct oral anticoagulant; ISTH, International Society on Thrombosis and Hemostasis; $\mathrm{CHADS}_{2}=$ (congestive heart failure, hypertension, age $\geq 75$ years), diabetes mellitus, stroke (double weight)); NMA, network meta-analysis; NVAF, nonvalvular atrial fibrillation; SLR, systematic literature review. ${ }^{a}$ Any network meta-analysis comparison of apixaban $2.5 \mathrm{mg}$ only with another DOAC was not included.

The search results were compared and the duplicates eliminated. An initial screening of the studies was performed on the basis of titles and abstracts, and then the full texts were reviewed by five. Five reviewers (D.A., P.S., C.A., V.C., and G.C.) independently performed the revision, while discrepancies were solved by a consensus, involving two additional authors (M.U., M.M.C.).

Data were derived from four pivotal trials (Figure 1). Details of the search strategy according to PRISMA-P were described in all of the tables in the supplementary materials section.

The RI was computed in terms of efficacy (rate of stroke-systemic embolism/rate of patients with and without diabetes) and safety (rate of major bleeding/rate of patients with and without diabetes; rate of cardiovascular death/rate of patients with and without diabetes) of DOACs and VKAs. 

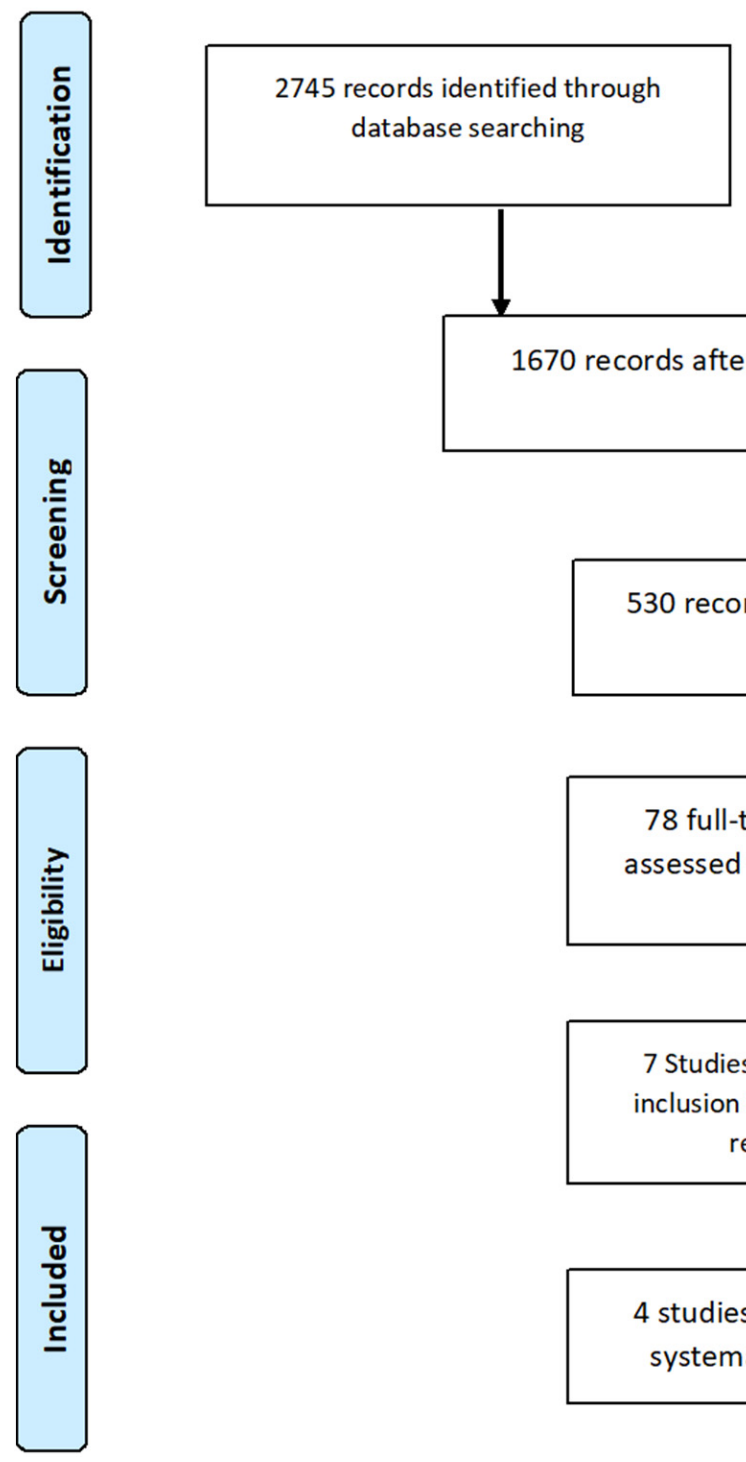

1670 records after duplicates removed

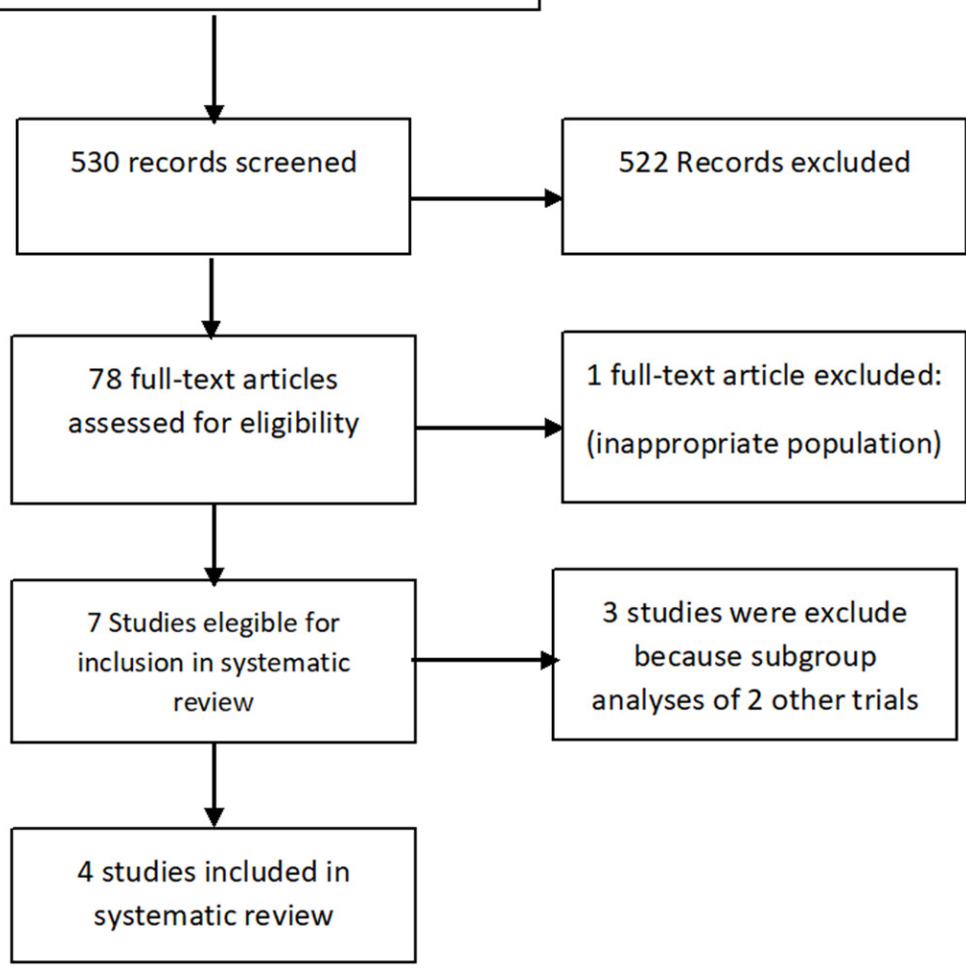

Figure 1. Preferred Reporting Items for Systematic Reviews and Meta-Analyses (PRISMA-P) flow diagram: search and selection process.

\section{Statistical Analysis}

No statistical analyses were conducted; according to the authors, indirect, comparative meta-analyses among DOACs are a hypothesis generator that cannot provide definitive answers.

Furthermore, the RI does not allow the comparisons of rates among nonhomogeneous studies.

\section{Main Results}

The main characteristics of the four RCTs involving DOACs are summarized in Table 2. About 22,057 patients with AF and DM and 49,596 AF patients without DM were finally included. The results of our systematic review are summarized in Table 3 . The percentages of patients with DM ranged from $23.3 \%$ to $39.9 \%$. The highest number of patients with DM was in the patient population treated with Rivaroxaban (40.3\%). 
Table 2. Main characteristics of the four DOACs pivotal trials.

\begin{tabular}{|c|c|c|c|c|}
\hline & $\begin{array}{l}\text { ROCKET AF } \\
\text { Rivaroxaban }\end{array}$ & $\begin{array}{l}\text { ARISTOTLE } \\
\text { Apixaban }\end{array}$ & $\begin{array}{c}\text { RE-LY } \\
\text { Dabigatran }\end{array}$ & $\begin{array}{l}\text { ENGAGE } \\
\text { Edoxaban }\end{array}$ \\
\hline Effect & Anti-Xa & Anti-Xa & Anti-IIa & Anti-Xa \\
\hline Dose & 20/15 mg QD & 5/2.5 mg BID & $150 / 110 \mathrm{mg}$ BID & $60 / 30 \mathrm{mg} Q D$ \\
\hline Mean $\mathrm{CHADS}_{2}$ score & 3.5 & 2.1 & 2.1 & 2.8 \\
\hline Target INR (Warfarin arm) & $2-3$ & $2-3$ & $2-3$ & $2-3$ \\
\hline TTR $(\%)$ & 58 & 62 & 64 & 68 \\
\hline Asia Pacific Region N (\%) & $2109(14.8 \%)$ & $2916(16 \%)$ & $3854(21 \%)$ & $3383(16 \%)$ \\
\hline Median Follow-up duration & $1.9 \mathrm{y}$ & $1.8 \mathrm{y}$ & $2 \mathrm{y}$ & $2.8 \mathrm{y}$ \\
\hline
\end{tabular}

ROCKET-AF = Rivaroxaban Once-daily oral direct factor Xa inhibition Compared with vitamin K antagonism for prevention of stroke and Embolism Trial in Atrial Fibrillation [17]; ARISTOTLE = Apixaban for Reduction in Stroke and Other Thromboembolic Events in Atrial Fibrillation [16]; RE-LY = Randomized Evaluation of Long-Term Anticoagulant Therapy [14]; ENGAGE-AF TIMI $48=$ Effective Anticoagulation With Factor Xa Next Generation in Atrial Fibrillation [15]; Xa = Factor X activated; IIa = Thrombin; QD = Quaque die; $\mathrm{BID}=$ Bis in die; $\mathrm{CHADS}_{2}=$ Congestive Heart Failure, Hypertension, Age, Diabetes, Stroke; INR = International Normalized Ratio; TTR = Time to Range; $\mathrm{N}=$ Number; $\mathrm{y}=$ year.

Table 3. Patients with and without diabetes in the pivotal trials.

\begin{tabular}{|c|c|c|c|c|c|c|}
\hline RCTs & $\begin{array}{c}\text { Pts on DOACs } \\
\text { (N) }\end{array}$ & $\begin{array}{c}\text { Diabetes } \\
\text { N (\%) }\end{array}$ & $\begin{array}{c}\text { No Diabetes } \\
\text { N (\%) }\end{array}$ & $\begin{array}{l}\text { Pts on } \\
\text { Warfarin } \\
\text { (N) }\end{array}$ & $\begin{array}{c}\text { Diabetes } \\
\text { N (\%) }\end{array}$ & $\begin{array}{c}\text { No Diabetes } \\
\text { N (\%) }\end{array}$ \\
\hline ROCKET AF & 7131 & $2878(40.3 \%)$ & $4253(59.7 \%)$ & 7133 & $2817(39.5 \%)$ & $4316(60.5 \%)$ \\
\hline ARISTOTLE & 9120 & $2284(25.0 \%)$ & $6836(75 \%)$ & 9087 & $2263(24.9 \%)$ & $6818(75.1 \%)$ \\
\hline RE-LY $110 \mathrm{mg}$ & 6015 & $1409(23.4 \%)$ & $4606(66.6 \%)$ & 6022 & $1410(23.4 \%)$ & $4612(66.6 \%)$ \\
\hline RE-LY $150 \mathrm{mg}$ & 6076 & $1402(23.1 \%)$ & $4674(63.9 \%)$ & 6022 & $1410(23.4 \%)$ & $4612(66.6 \%)$ \\
\hline ENGAGE $_{30 \mathrm{mg}}$ & 7034 & $2544(36.2 \%)$ & $4490(63.8 \%)$ & 7036 & $2521(35.8 \%)$ & $4515(64.2 \%)$ \\
\hline ENGAGE $_{60 \mathrm{mg}}$ & 7035 & $2529(35.9 \%)$ & $4476(64.1 \%)$ & 7036 & $2521(35.8 \%)$ & $4515(64.2 \%)$ \\
\hline
\end{tabular}

RCTs = randomized controlled trials; DOACs = non-VKA antagonist drugs; Pts = Patients; $\mathrm{N}=$ Number; ROCKET-AF = Rivaroxaban Once-daily oral direct factor Xa inhibition Compared with vitamin $\mathrm{K}$ antagonism for prevention of stroke and Embolism Trial in Atrial Fibrillation [17]; ARISTOTLE = Apixaban for Reduction in Stroke and Other Thromboembolic Events in Atrial Fibrillation [16]; RE-LY = Randomized Evaluation of Long-Term Anticoagulant Therapy [14]; ENGAGE-AF TIMI 48 = Effective Anticoagulation With Factor Xa Next Generation in Atrial Fibrillation [15].

Table 4 summarized data regarding the rate of stroke/SEE, major bleeding, and CV death related to warfarin, Dabigatran $110 \mathrm{mg}$ and $150 \mathrm{mg}$ BID, Rivaroxaban $20 \mathrm{mg}$ QD, Apixaban $5 \mathrm{mg}$ BID, and Edoxaban high and low dose (60-30 mg) QD.

The RIs for stroke/SEE and CV death were similar between patients treated with DOACs and patients treated with warfarin (Figures 2 and 3, Table 5), except for Edoxaban $30 \mathrm{mg}$ QD, which showed a higher RI than warfarin for stroke/SEE. Indeed, Rivaroxaban QD had the lowest RI values in terms of both stroke/SEE and CV death (Figures 2 and 3, Table 5). Nevertheless, no data about CV death were reported for Edoxaban low doses, as none of the patients on Edoxaban low dose were included in the pivotal RCT (Table 5). 
Table 4. Stroke/systemic embolism, major bleeding, and cardiovascular death in patients with and without diabetes in the pivotal trials.

\begin{tabular}{|c|c|c|c|c|c|c|}
\hline \multicolumn{7}{|c|}{ Diabetes } \\
\hline \multirow[t]{2}{*}{ RCTs } & \multicolumn{2}{|c|}{ Stroke o SEE $(\mathrm{N}) \%$} & \multicolumn{2}{|c|}{$\mathrm{MB}(\mathrm{N}) \%$} & \multicolumn{2}{|c|}{ CV Death N (\%) } \\
\hline & DOACs & Warfarin & DOACs & Warfarin & DOACs & Warfarin \\
\hline ROCKET AF & $95(3.3 \%)$ & $114(4.0 \%)$ & $165(5.7 \%)$ & $169(6.0 \%)$ & $152(5.3 \%)$ & $192(6.8 \%)$ \\
\hline ARISTOTLE & $57(2.5 \%)$ & $75(3.3 \%)$ & $112(4.9 \%)$ & $114(5.0 \%)$ & $79(3.5 \%)$ & $88(3.9 \%)$ \\
\hline RE-LY $_{110}$ & $49(3.5 \%)$ & $64(4.5 \%)$ & $106(7.5 \%)$ & $114(8.0 \%)$ & $91(6.5 \%)$ & $109(7.7 \%)$ \\
\hline RE-LY $_{150}$ & $40(2.9 \%)$ & & $129(9.2 \%)$ & & $95(6.8 \%)$ & \\
\hline ENGAGE $_{30 \mathrm{mg}}$ & $135(5.3 \%)$ & $107(4.2 \%)$ & $123(4.9 \%)$ & $278(11 \%)$ & $\mathrm{NA}$ & NA \\
\hline ENGAGE $_{60 \mathrm{mg}}$ & $102(4.0 \%)$ & & $219(8.6 \%)$ & & $209(8.1 \%)$ & $219(8.6 \%)$ \\
\hline \multicolumn{7}{|c|}{ No Diabetes } \\
\hline RCTs & \multicolumn{2}{|c|}{ Stroke o SEE (N)\% } & \multicolumn{2}{|c|}{$\mathrm{MB}(\mathrm{N}) \%$} & \multicolumn{2}{|c|}{ CV Death N (\%) } \\
\hline ROCKET AF & $174(4.0 \%)$ & $192(4.4 \%)$ & $230(5.4 \%)$ & $217(5.0 \%)$ & $223(5.2 \%)$ & $209(4.8 \%)$ \\
\hline ARISTOTLE & $155(2.3 \%)$ & $190(2.8 \%)$ & $215(3.2 \%)$ & $348(5.1 \%)$ & $229(3.4 \%)$ & $256(3.7 \%)$ \\
\hline RE-LY $_{110}$ & $134(2.9 \%)$ & $138(2.9 \%)$ & $236(5.1 \%)$ & $307(6.6 \%)$ & $198(4.3 \%)$ & $208(4.5 \%)$ \\
\hline RE-LY $_{150}$ & $94(2.0 \%)$ & & $271(5.8 \%)$ & & $179(3.8 \%)$ & \\
\hline ENGAGE $_{30 \mathrm{mg}}$ & NA & NA & NA & NA & NA & NA \\
\hline ENGAGE $_{60 \mathrm{mg}}$ & $207(4.6 \%)$ & $248(5.4 \%)$ & $335(7.5 \%)$ & $417(9.2 \%)$ & $331(7.4 \%)$ & $406(8.9 \%)$ \\
\hline
\end{tabular}

RCTs = randomized controlled trials; DOAC = non-VKA antagonist drugs; $\mathrm{N}=$ Number; $\mathrm{SEE}=$ systemic embolism $\mathrm{MB}=$ major bleeding; $\mathrm{CV}=$ cardiovascular death; ROCKET-AF = Rivaroxaban Once-daily oral direct factor Xa inhibition Compared with vitamin K antagonism for prevention of stroke and Embolism Trial in Atrial Fibrillation [17]; ARISTOTLE = Apixaban for Reduction in Stroke and Other Thromboembolic Events in Atrial Fibrillation [16] RE-LY = Randomized Evaluation of Long-Term Anticoagulant Therapy [14]; ENGAGE-AF TIMI 48 = Effective Anticoagulation With Factor Xa Next Generation in Atrial Fibrillation [15].

Table 5. Risk index of stroke/systemic embolism, major bleeding, and cardiovascular death in patients with and without diabetes in the pivotal trials.

\begin{tabular}{|c|c|c|c|c|c|c|}
\hline \multicolumn{7}{|c|}{ Diabetes } \\
\hline \multirow[t]{2}{*}{ RCTs } & \multicolumn{2}{|c|}{ Stroke o SEE } & \multicolumn{2}{|c|}{ MB } & \multicolumn{2}{|c|}{ CV Death } \\
\hline & DOACs & Warfarin & DOACs & Warfarin & DOACs & Warfarin \\
\hline ROCKET AF & 0.08 & 0.10 & 0.14 & 0.15 & 0.13 & 0.17 \\
\hline ARISTOTLE & 0.10 & 0.13 & 0.19 & 0.20 & 0.14 & 0.15 \\
\hline RE-LY $_{110}$ & 0.14 & 0.19 & 0.32 & 0.34 & 0.27 & 0.33 \\
\hline RE-LY $_{150}$ & 0.12 & & 0.40 & & 0.29 & \\
\hline ENGAGE $_{30 \mathrm{mg}}$ & 0.15 & 0.12 & 0.13 & 0.30 & NA & NA \\
\hline ENGAGE $_{60 \mathrm{mg}}$ & 0.11 & & 0.23 & & 0.22 & 0.24 \\
\hline \multicolumn{7}{|c|}{ No Diabetes } \\
\hline RCTs & \multicolumn{2}{|c|}{ Stroke o SEE } & \multicolumn{2}{|c|}{ MB } & \multicolumn{2}{|c|}{ CV Death } \\
\hline ROCKET AF & 0.06 & 0.07 & 0.09 & 0.08 & 0.08 & 0.08 \\
\hline ARISTOTLE & 0.03 & 0.03 & 0.04 & 0.06 & 0.04 & 0.04 \\
\hline RE-LY $_{110}$ & 0.04 & 0.04 & 0.07 & 0.09 & 0.06 & 0.06 \\
\hline RE-LY 150 & 0.03 & & 0.09 & & 0.06 & \\
\hline ENGAGE $_{30 \mathrm{mg}}$ & NA & NA & NA & NA & NA & NA \\
\hline ENGAGE $_{60 \mathrm{mg}}$ & 0.07 & 0.08 & 0.11 & 0.14 & 0.11 & 0.13 \\
\hline
\end{tabular}

RCTs = randomized controlled trials; $\mathrm{N}=$ Number; $\mathrm{SEE}=$ systemic embolism; $\mathrm{MB}=$ major bleeding; $\mathrm{CV}=$ cardiovascular death; $\mathrm{DOAC}=$ non-VKA antagonist drugs; $\mathrm{ROCKET}-\mathrm{AF}=$ Rivaroxaban Once-daily oral direct factor Xa inhibition Compared with vitamin K antagonism for prevention of stroke and Embolism Trial in Atrial Fibrillation [17]; ARISTOTLE = Apixaban for Reduction in Stroke and Other Thromboembolic Events in Atrial Fibrillation [16]; RE-LY = Randomized Evaluation of Long-Term Anticoagulant Therapy [14]; ENGAGE-AF TIMI $48=$ Effective Anticoagulation With Factor Xa Next Generation in Atrial Fibrillation [15]. 


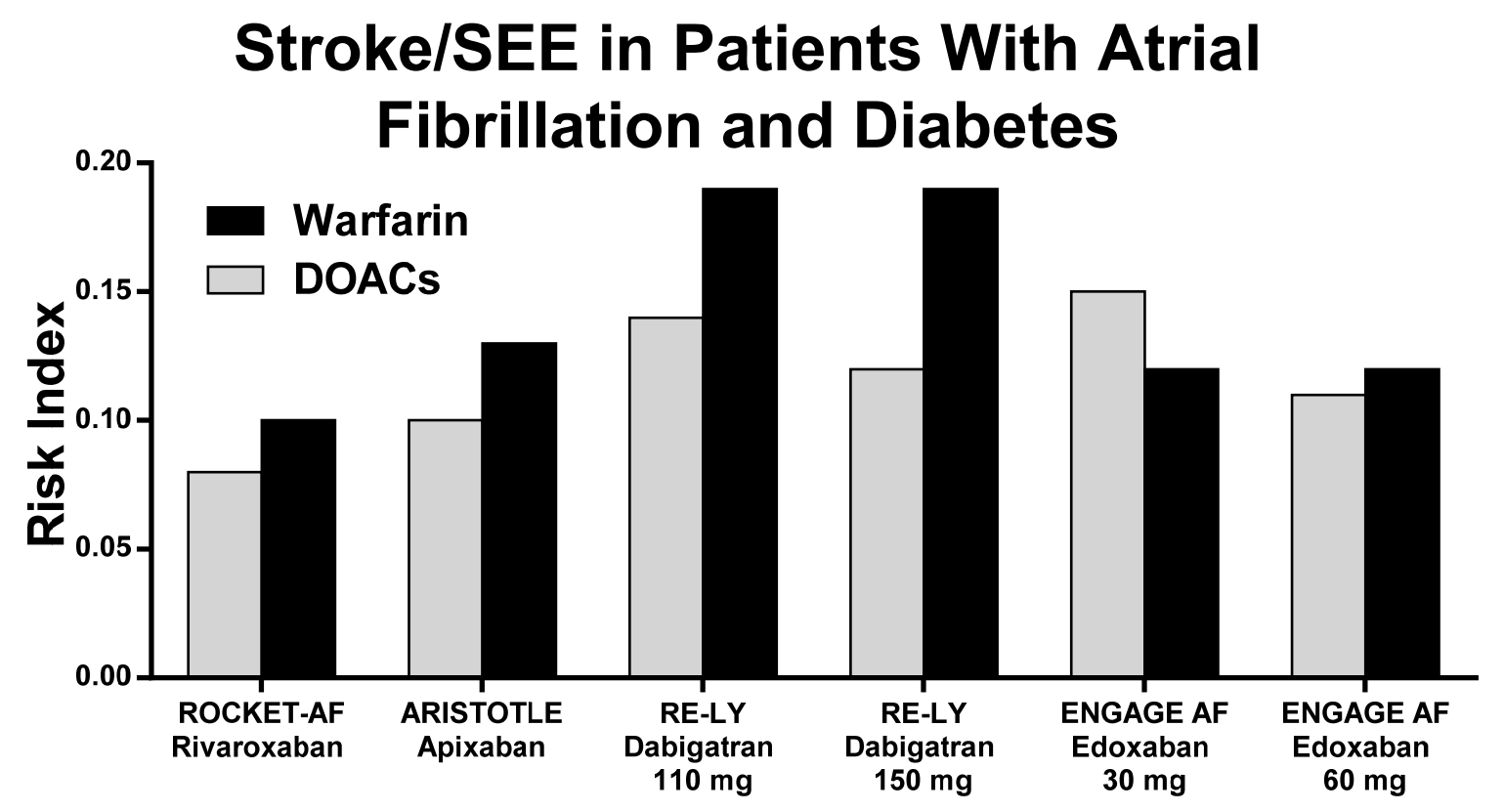

(A)

\section{Stroke/SEE in Patients With Atrial} Fibrillation No Diabetes

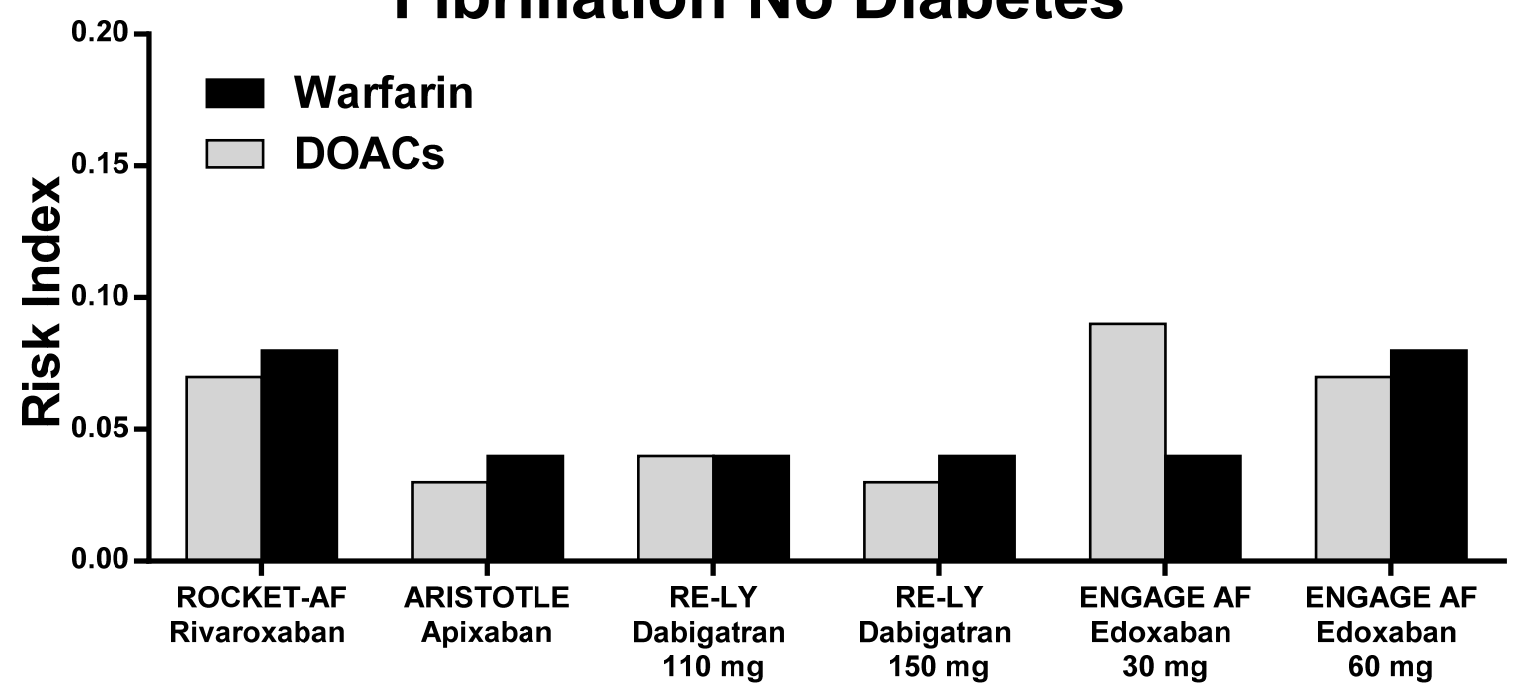

(B)

Figure 2. Risk index of stroke/systemic embolism in patients with (A) and without (B) diabetes in the pivotal trials. 


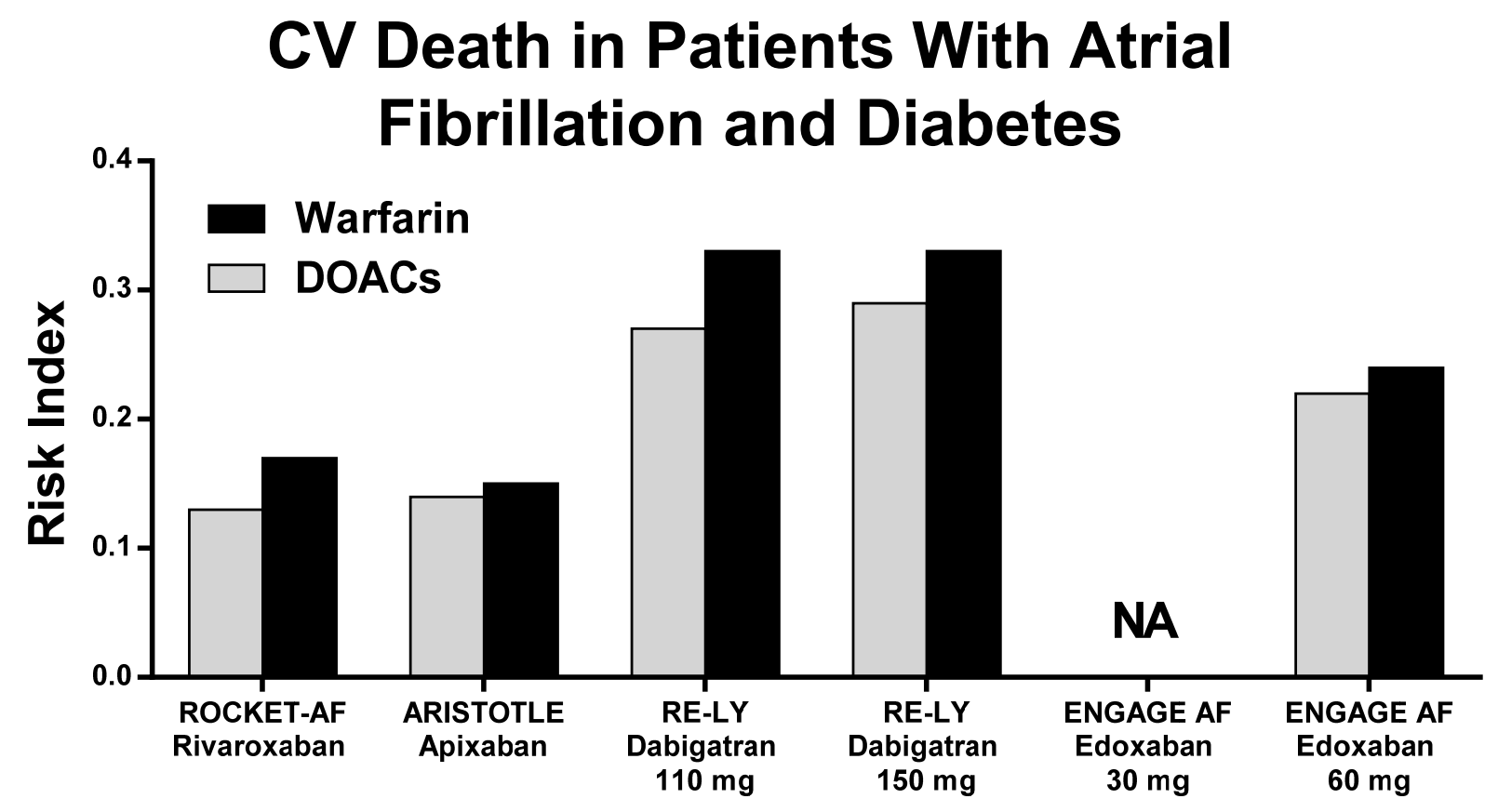

(A)

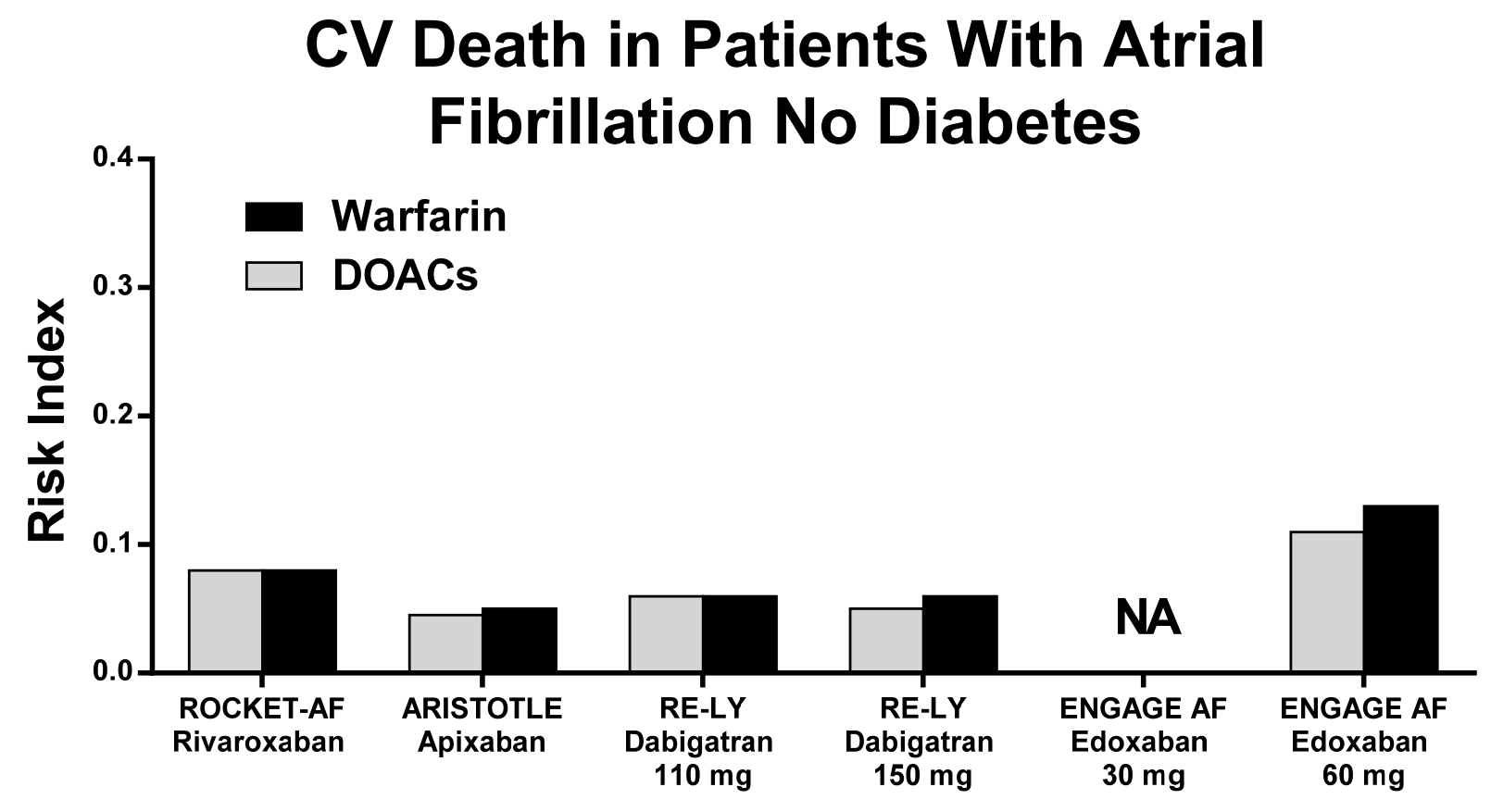

(B)

Figure 3. Risk index of CV Death in patients with (A) and without (B) diabetes in the pivotal trials.

The RIs for major bleedings are shown in Table 5 and Figure 4. Dabigatran $150 \mathrm{mg}$ BID showed a higher risk for bleeding compared to warfarin, while other DOACs showed substantially equal RIs in comparison with warfarin (Table 5 and Figure 4). No DM patients with AF as compared to DM patients without AF showed lower RIs (Table 5, Figures 2-4). 


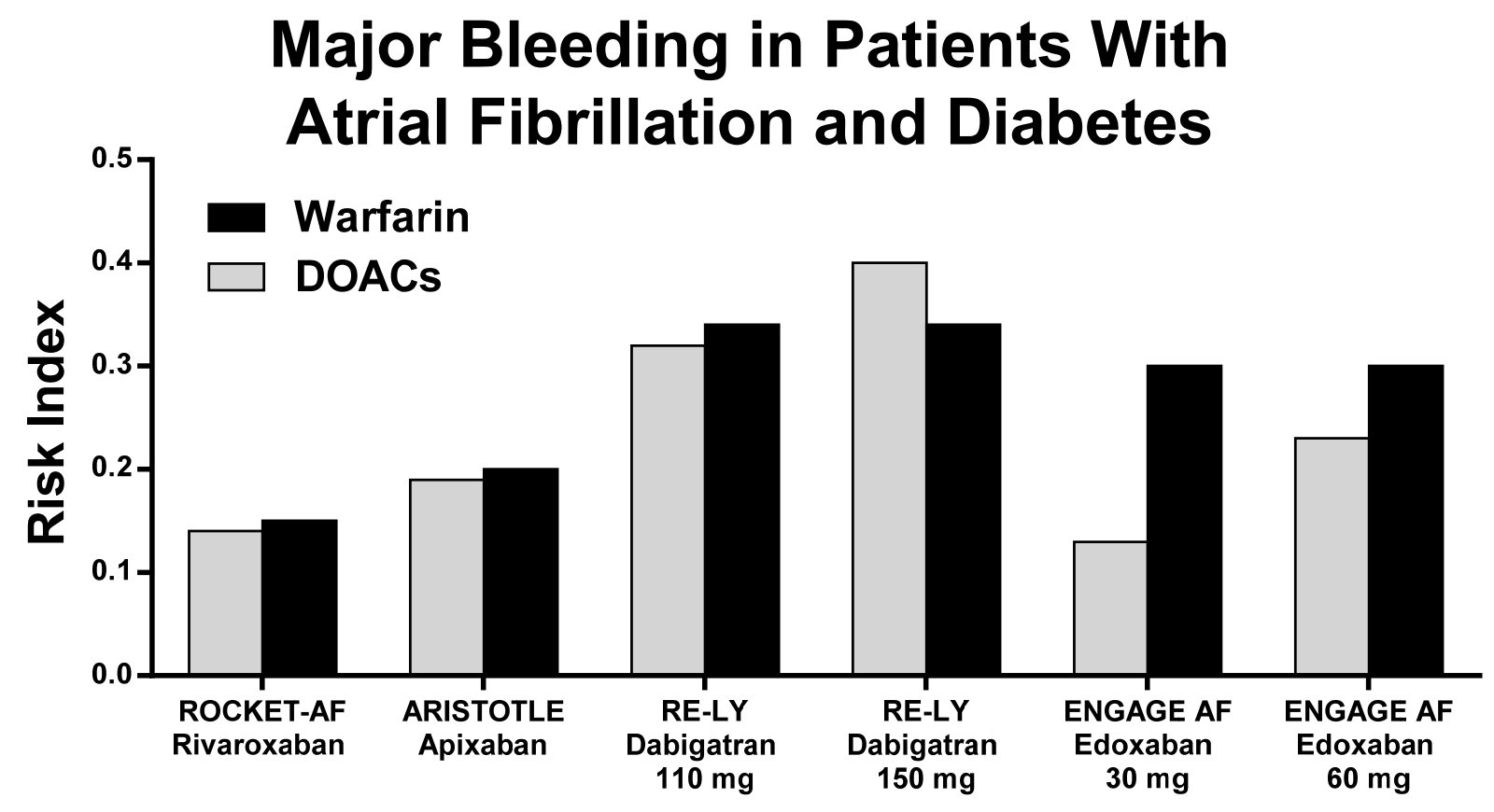

(A)

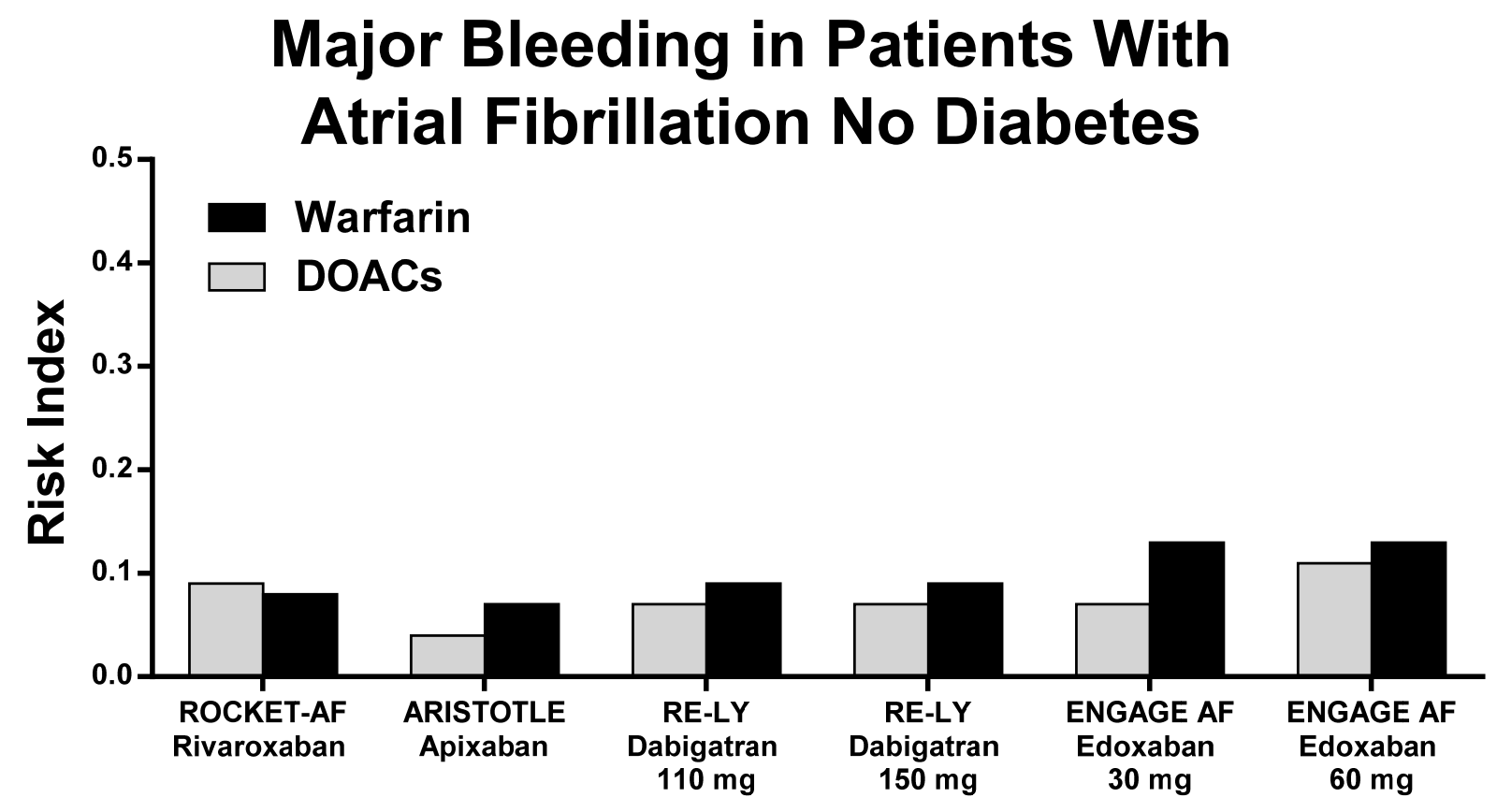

(B)

Figure 4. Risk index of Major Bleeding in patients with (A) and without (B) diabetes in the pivotal trials.

\section{Discussion}

Diabetes mellitus per se increases the risk of systemic stroke/embolism or cardiovascular death in patients with atrial fibrillation [21]. Therefore, anticoagulant therapy is mandatory in these patients [22]. Choosing the correct anticoagulant therapy in patients with AF is a challenge, especially in patients at higher risk such as DM patients. DM and AF are two sides of the same coin due to the tight correlation between these two pathological conditions [4]. The frequency of NVAF increases by $40 \%$ in patients with Type 2 diabetes, 
while thromboembolic risk is $79 \%$ higher compared to non-diabetic patients [14,22-24]. Indeed, both conditions can potentiate their negative effects on systemic tissue and organs: for example, they can both promote kidney failure $[25,26]$. In such a setting, choosing the correct anticoagulation remains challenging as these drugs may also promote systemic alterations. Warfarin, the traditional anticoagulant used to prevent thromboembolism, can also be dangerous due to a supposed negative influence on kidneys and systemic vessels by promoting arterial calcification and decreasing renal function [27]. Indeed, DOACs seemed to be safer and more efficacious [27], especially when dealing with Type 2 diabetic patient [22-24].

Using RI as suggested by Uguccioni et al. could help reduce heterogeneity enrolled in RCTs and provide a better approach for the selection of the correct anticoagulant based on the different patient characteristics $[19,20]$. In particular, an RI lower than 1 suggests a favorable treatment effect. The lower the RI value, the better the performance of the drug within the specific context $[19,20]$. This is the first report that evaluates the risk for stroke/SEE, CV death, and major bleeding in patients with AF with and without DM by means of RI.

In our study, both DOACs and warfarin appear to be effective in preventing stroke and systemic embolism, with lower rates of $\mathrm{CV}$ death and major bleeding. The RI of each drug is lower than one, although some differences should be outlined. In particular, Dabigatran $150 \mathrm{mg}$ BID might increase major bleeding risk as compared to warfarin, while the risk for stroke/SEE seems higher with Edoxaban $30 \mathrm{mg}$ QD as compared to warfarin in DM patients. These data are the most contradictory in the panel of RIs comparisons as all of the other drugs and dosages revealed protective and efficient effects on patients' outcomes as compared to warfarin (Figures 2 and 4). By considering the absolute measurements, Rivaroxaban QD demonstrated the lowest RI value in terms of stroke/SEE outcomes, while Edoxaban $30 \mathrm{mg}$ QD showed the lowest RI in terms of major bleeding outcomes, although no data are reported on pivotal Edoxaban Low Dose RCT with regard to CV death in patients with and without DM.

The literature offers evidence about the DOACs performances in AF patients in terms of efficacy and safety, but the reproducibility of the data and indirect comparisons among drugs may interfere with the correct choice of anticoagulants [28]. A meta-analysis by Ruff et al. involving the 71,683 patients with AF from registration RCTs showed a significant reduction in the incidence of stroke and SEE (relative risk (RR) 0.81, confidence interval (CI) $95 \% 0.73-0.91 ; p<0.0001)$ in patients with DOACs versus warfarin, as well as all-cause mortality (RR 0.90, CI 95\% 0.85-0.95; $p=0.0003$ ) and intracranial hemorrhages (RR 0.48, 95\% CI 0.39-0:59; $p<0.0001$ ), despite the increase in gastrointestinal bleeding (RR 1.25, 95\% CI 1.01-1.55; $p=0.04)$ [18].

\section{Study Limitations}

Unfortunately, a number of methodological discrepancies, including study design, different selection of the populations, and different definitions of outcomes among the four phase-III RCTs, reduce the generalization of results and the comparisons among drugs [14-17]. The selection of DM patients among RCTs populations aimed at evaluating a uniform subset of individuals.

Registration studies differ in terms of thromboembolic risk of the enrolled populations, age, heart failure, and active cancer. Active cancer is a high thromboembolic risk condition, and DAOCs appear to be an effective and safe therapeutic option in these patients [29]. The highest rate of DM patients was in Rocket-AF (40\%) while ARISTOTLE had 25\% and RE-LY had $23 \%$.

The incidence of major bleeding was similar in AF patients with DM treated with Rivaroxaban or warfarin, while increasing when Dabigatran 110 mg, Dabigatran 150 mg, or warfarin were adopted. This difference might be associated with patients' risk profiles, as well as other factors that may influence the pharmacokinetics and pharmacodynamics (co-morbidities, advanced age, HF, diabetes, hepatic or renal insufficiency). RCTs did 
not provide routine information about blood glucose levels and $\mathrm{HbA}_{1 \mathrm{c}}$, while patients with creatinine clearance $<30 \mathrm{~mL} /$ min were excluded. Therefore, patients with severe diabetic nephropathy, who are at even higher risk for cardiovascular complications, were excluded from RCTs. In these RCTs, no interactions were found between diabetic status and clinical efficacy of DOACs versus warfarin. Interestingly, the superiority of Apixaban over warfarin in terms of safety was lost when patients with AF and DM were considered ( $p=0.003$ for interaction) [30]. Moreover, a study-level meta-analysis in patients with $\mathrm{DM}$ and $\mathrm{AF}$ demonstrated a significant reduction in stroke and systemic embolism event rates $(-20 \%)$ in patients treated with DOACs as compared to warfarin, as well as vascular mortality $(-17 \%)$ and intracranial bleeding $(-43 \%)$, while no influence was observed in terms of incidence of major bleeding [23].

We did not conduct any statistical analyses; indirect, comparative meta-analyses among DOACs are hypothesis generators and cannot provide definitive answers.

Conversely, it has been shown that published RCT data can be affected by the insertion of controversial data. In addition, they could invalidate the medical literature, alter the results of meta-analyses, and consequently compromise future research, political decisions, and above all patient care [31].

\section{Conclusions}

To our knowledge, no data are available about direct comparisons between DOACs in patients with DM. The choice of DOAC in patients with DM is not supported by specific evidence, but it should be guided by general principles, taking into account age and comorbidities (hypertension, coronary artery disease, heart failure, kidney disease, obesity, and dyslipidemia).

Diabetic patients show a doubled RI compared to non-diabetic patients. Data from the systematic evaluation of the four phase-III RCTs with DOACs in patients with AF and DM showed that Rivaroxaban had the lowest RI with regard to MB, CV death, and stroke/SEE. The use of DOACs is a reasonable alternative to VKAs in the management of patients with $\mathrm{AF}$ and DM. The risk index is a useful additional tool to help clinicians to choose DOACs or warfarin in a particular category of AF patients.

Supplementary Materials: The following are available online at https:/ / www.mdpi.com/article/10 .3390/jcm10132924/s1, File S1: The search strategy according to PRISMA-P.

Author Contributions: D.A., M.M.C., C.A., V.C., G.C., A.S.B., M.U., and P.S. devised and designed the study, collected and interpreted the data, drafted the article and critically reviewed its content, and approved the final version for publication. All authors have read and agreed to the published version of the manuscript.

Funding: The authors received no financial support for the research, authorship, and/or publication of this article.

Data Availability Statement: Data are available on request by contacting the corresponding author.

Conflicts of Interest: The authors declare that there is no conflict of interests. None of the authors have any financial or other relations that could lead to a conflict of interest.

\section{References}

1. Go, A.S.; Hylek, E.M.; Phillips, K.A.; Chang, Y.; Henault, L.E.; Selby, J.V.; Singer, D.E. Prevalence of diagnosed atrial fibrillation in adults: National implications for rhythm management and stroke prevention: The AnTicoagulation and Risk Factors in Atrial Fibrillation (ATRIA) Study. JAMA 2001, 285, 2370-2375. [CrossRef]

2. GBD 2016 Disease and Injury Incidence and Prevalence Collaborators. Global, regional, and national incidence, preva-lence, and years lived with disability for 328 diseases and injuries for 195 countries, 1990-2016: A systematic analysis for the Global Burden of Disease Study 2016. Lancet 2017, 390, 1211-1259.

3. GBD 2016 Causes of Death Collaborators. Global, regional, and national age-sex specific mortality for 264 causes of death, 1980-2016: A systematic analysis for the Global Burden of Disease Study 2016. Lancet 2017, 390, 1151-1210. [CrossRef]

4. Bell, D.S.H.; Goncalves, E. Atrial fibrillation and type 2 diabetes: Prevalence, etiology, pathophysiology and effect of an-ti-diabetic therapies. Diabetes Obes. Metab. 2019, 21, 210-217. [CrossRef] [PubMed] 
5. Benjamin, E.J.; Levy, D.; Vaziri, S.M.; D’Agostino, R.B.; Belanger, A.J.; Wolf, P.A. Independent risk factors for atrial fibrillation in a population-based cohort. The Framingham Heart Study. JAMA 1994, 271, 840-844. [CrossRef] [PubMed]

6. Haywood, L.J.; Ford, C.E.; Crow, R.S.; Davis, B.R.; Massie, B.M.; Einhorn, P.T.; Williard, A. Atrial Fibrillation at Baseline and During Follow-Up in ALLHAT (Antihypertensive and Lipid-Lowering Treatment to Prevent Heart Attack Trial). J. Am. Coll. Cardiol. 2009, 54, 2023-2031. [CrossRef]

7. Aksnes, T.A.; Schmieder, R.E.; Kjeldsen, S.E.; Ghani, S.; Hua, T.A.; Julius, S. Impact of new-onset diabetes mellitus on development of atrial fibrillation and heart failure in high-risk hypertension (from the VALUE Trial). Am. J. Cardiol. 2008, 101, 634-638. [CrossRef] [PubMed]

8. Murphy, N.F.; Simpson, C.; Jhund, P.; Stewart, S.; Kirkpatrick, M.; Chalmers, J.; Macintyre, K.; McMurray, J.J.V. A national survey of the prevalence, incidence, primary care burden and treatment of atrial fibrillation in Scotland. Heart 2007, 93, 606-612. [CrossRef] [PubMed]

9. Chung, M.K.; Eckhardt, L.L.; Chen, L.Y.; Ahmed, H.M.; Gopinathannair, R.; Joglar, J.A.; Noseworthy, P.A.; Pack, Q.R.; Sanders, P.; Trulock, K.M. Lifestyle and Risk Factor Modification for Reduction of Atrial Fibrillation: A Scientific Statement From the American Heart Association. Circulation 2020, 141, e750-e772. [CrossRef] [PubMed]

10. Ceriello, A.; Giacomello, R.; Stel, G.; Motz, E.; Taboga, C.; Tonutti, L.; Pirisi, M.; Falleti, E.; Bartoli, E. Hyperglycemia-induced thrombin formation in diabetes. The possible role of oxidative stress. Diabetes 1995, 44, 924-928. [CrossRef] [PubMed]

11. Lee, S.; Ay, C.; Kopp, C.W.; Panzer, S.; Gremmel, T. Impaired glucose metabolism is associated with increased thrombin generation potential in patients undergoing angioplasty and stenting. Cardiovasc. Diabetol. 2018, 17, 131. [CrossRef] [PubMed]

12. Baraka-Vidot, J.; Guerin-Dubourg, A.; Bourdon, E.; Rondeau, P. Impaired drug-binding capacities of in vitro and in vivo glycated albumin. Biochimie 2012, 94, 1960-1967. [CrossRef] [PubMed]

13. Nelson, W.W.; Desai, S.; Damaraju, C.V.; Lu, L.; Fields, L.E.; Wildgoose, P.; Schein, J.R. International normalized ratio stability in warfarin-experienced patients with nonvalvular atrial fbrillation. Am. J. Cardiovasc. Drugs 2015, 15, 205-211. [CrossRef] [PubMed]

14. Connolly, S.J.; Ezekowitz, M.D.; Yusuf, S.; Eikelboom, J.; Oldgren, J.; Parekh, A.; Pogue, J.; Reilly, P.A.; Themeles, E.; Varrone, J.; et al. Dabigatran versus Warfarin in Patients with Atrial Fibrillation. N. Engl. J. Med. 2009, 361, 1139-1151. [CrossRef] [PubMed]

15. Giugliano, R.P.; Ruff, C.T.; Braunwald, E.; Murphy, A.; Wiviott, S.D.; Halperin, J.L.; Waldo, A.L.; Ezekowitz, M.D.; Weitz, J.I.; Špinar, J.; et al. Edoxaban versus Warfarin in Patients with Atrial Fibrillation. N. Engl. J. Med. 2013, 369, 2093-2104. [CrossRef] [PubMed]

16. Granger, C.B.; Alexander, J.H.; McMurray, J.J.V.; Lopes, R.D.; Hylek, E.M.; Hanna, M.; Al-Khalidi, H.R.; Ansell, J.; Atar, D.; Avezum, A.; et al. Apixaban versus warfarin in patients with atrial fibrillation. N. Engl. J. Med. 2011, 365, 981-992. [CrossRef] [PubMed]

17. Patel, M.R.; Mahaffey, K.W.; Garg, J.; Pan, G.; Singer, D.E.; Hacke, W.; Breithardt, G.; Halperin, J.L.; Hankey, G.J.; Piccini, J.P.; et al. Rivaroxaban versus warfarin in nonvalvular atrial fibrillation. N. Engl. J. Med. 2011, 365, 883-891. [CrossRef] [PubMed]

18. Ruff, C.T.; Giugliano, R.P.; Braunwald, E.; Hoffman, E.B.; Deenadayalu, N.; Ezekowitz, M.D.; Camm, A.J.; Weitz, J.I.; Lewis, B.S.; Parkhomenko, A.; et al. Comparison of the efficacy and safety of new oral anticoagulants with warfarin in patients with atrial fibrillation: A meta-analysis of randomised trials. Lancet 2014, 383, 955-962. [CrossRef]

19. Acanfora, D.; Ciccone, M.M.; Scicchitano, P.; Ricci, G.; Acanfora, C.; Uguccioni, M.; Casucci, G. Efficacy and Safety of Direct Oral Anticoagulants in Patients With Atrial Fibrillation and High Thromboembolic Risk. A Systematic Review. Front. Pharmacol. 2019, 10, 1048. [CrossRef] [PubMed]

20. Uguccioni, M.; Terranova, A.; Di Lullo, L. Valutazione delle reazioni avverse agli anticoagulanti orali diretti registrate nella Rete Nazionale di Farmacovigilanza mediante uno specifico indice di rischio. Ital. Cardiol. 2018, 19, 3-11.

21. Du, X.; Ninomiya, T.; De Galan, B.; Abadir, E.; Chalmers, J.; Pillai, A.; Woodward, M.; Cooper, M.; Harrap, S.; Hamet, P.; et al. Risks of cardiovascular events and effects of routine blood pressure lowering among patients with type 2 diabetes and atrial fibrillation: Results of the ADVANCE study. Eur. Hear. J. 2009, 30, 1128-1135. [CrossRef]

22. Patti, G.; Cavallari, I.; Andreotti, F.; Calabrò, P.; Cirillo, P.; Denas, G.; Galli, M.; Golia, E.; Maddaloni, E.; Marcucci, R.; et al. Prevention of atherothrombotic events in patients with diabetes mellitus: From antithrombotic therapies to new-generation glucose-lowering drugs. Nat. Rev. Cardiol. 2019, 16, 113-130. [CrossRef] [PubMed]

23. Patti, G.; Di Gioia, G.; Cavallari, I.; Nenna, A. Safety and efficacy of nonvitamin K antagonist oral anticoagulants versus warfarin in diabetic patients with atrial fibrillation: A study-level meta-analysis of phase III randomized trials. Diabetes Metab. Res. Rev. 2017, 33, e2876. [CrossRef] [PubMed]

24. Stroke Risk in Atrial Fibrillation Working Group. Independent predictors of stroke in patients with atrial fibrillation: A systematic review. Neurology 2007, 69, 546-554. [CrossRef] [PubMed]

25. Braunwald, E. Diabetes, heart failure, and renal dysfunction: The vicious circles. Prog. Cardiovasc. Dis. 2019, 62, 298-302. [CrossRef] [PubMed]

26. Hu, L.; Xiong, Q.; Chen, Z.; Fu, L.; Hu, J.; Chen, Q.; Tu, W.; Xu, C.; Xu, G.; Li, J.; et al. Factors Associated with a Large Decline in Renal Function or Progression to Renal Insufficiency in Hospitalized Atrial Fibrillation Patients with Early-Stage CKD. Int. Hear. J. 2020, 61, 239-248. [CrossRef] [PubMed]

27. Yao, X.; Tangri, N.; Gersh, B.J.; Sangaralingham, L.R.; Shah, N.D.; Nath, K.A.; Noseworthy, P.A. Renal Outcomes in Anticoagulated Patients With Atrial Fibrillation. J. Am. Coll. Cardiol. 2017, 70, 2621-2632. [CrossRef] [PubMed] 
28. Acanfora, D.; Casucci, G.; Ciccone, M.M.; Scicchitano, P.; Montefusco, G.; Lanzillo, A.; Acanfora, C.; Lanzillo, B. Direct Oral Anti-coagulants, Bleeding Risk in Patients with Atrial Fibrillation, CHADS2 $\geq 3$ or HAS-BLED $\geq 3$. Cardiovasc. Pharm. 2018, 240, $2-4$.

29. Pacholczak-Madej, R.; Bazan-Socha, S.; Zaręba, L.; Undas, A.; Dropiński, J. Direct oral anticoagulants in the prevention of stroke in breast cancer patients with atrial fibrillation during adjuvant endocrine therapy: A cohort study. Int. J. Cardiol. 2021, 324, 78-83. [CrossRef] [PubMed]

30. Zadok, O.I.B.; Eisen, A. Use of non-vitamin K oral anticoagulants in people with atrial fibrillation and diabetes mellitus. Diabetes Med. 2018, 35, 548-556. [CrossRef] [PubMed]

31. Garmendia, C.A.; Nassar Gorra, L.; Rodriguez, A.L.; Trepka, M.J.; Veledar, E.; Madhivanan, P. Evaluation of the inclusion of studies identified by the FDA as having falsified data in the results of meta-analyses: The example of the apixaban trials. JAMA Int. Med. 2019, 179, 582-584. [CrossRef] [PubMed] 